\title{
THE NON-LINGUISTIC CONTEXT - A BRIDGE TO LINGUISTIC ITEMS AND PHENOMENA
}

\author{
Miroslava Tsvetkova*
}

\begin{abstract}
Each language is a complex system, which represents the world in a unique way, with its own stock of sounds, words, and phrases, as well as with its own grammatical constructions. The aim of the article is to prove that the non-linguistic context is a good way to improve the acquisition of linguistic items and phenomena and that our non-linguistic experience can affect the way we perceive language.
\end{abstract}

The study proves that language, perception, and thought are interdependent and the direction of interaction can go both from linguistic to non-linguistic patterns and vice versa.

The question of language and thought needs to extend not only to whether language affects thought, but whether non-linguistic patterns can affect the way language is perceived.

Key words: linguistic item, perception, thought, interaction.

\section{Introduction}

Every human being has the biological capacity to learn a language. When they stop to think of the mystery of how the first language is acquired, they will be fascinated by the incredibility of this phenomenon. It is believed that this is natural and it is going to happen, unless biologically disturbed. Each language is a complex system, which represents the world in a unique way, with its own stock of sounds, words and phrases, and its own grammatical constructions. The starting point of the study is the idea that each lexical or grammatical item can be explained through an item from the real world which builds the bridge between linguistic and non-linguistic items and phenomena.

Cognitive linguistics often explains the linguistic facts beyond the linguistic reality and, what is more, they gain non-linguistic nature - social, cultural, psychological, etc.

Since the study is part of a larger project "Linguistic and cognitive aspects of young learners' foreign language acquisition", it uses data and examples from the research while attempting to prove that non-linguistic context is a good way

\footnotetext{
* Assist. Professor PhD at Shumen University, Department of English Studies, Shumen, Bulgaria, e-mail: m.tsvetkova@shu.bg.
} 
to improve the acquisition of linguistic items and phenomena and that our nonlinguistic experience can affect the way we perceive language. The types of linguistic phenomena range from general concepts to types of relations between words or between a word and a phrase to specific constructions.

In her previous research in the field, the author of the article proves that the cognitive approach facilitates the comparison between familiar and new knowledge, the acquisition of grammatical rules, memorisation and use of language. "The cognitive stress is on using a model with high cognitive value, which develops and improves logical thinking and encourages imagination in its implementation. Thus, it aims to convert students from passive recipients to active constructors of knowledge." (Tsvetkova 2016: 126)

The first utterances of children are almost always associated with their understanding. They talk about things that attracted their attention and which are associated with sensorimotor circuits. So their language depends directly on their cognitive experience.

The relationship between language symbols and the intangible world provokes ideas which are not thoroughly studied. The questions to be discussed concern a two-sided process of experience. On one hand, it is the non-linguistic perception that can influence language acquisition and on the other hand, the different linguistic descriptions of the same scene can evoke different images.

The literature review relevant to the study determines the problems and flaws in the existing topic. It enables us to place this study in a larger context so that we can show what new conclusions might result from it.

\section{Relationship between language skills and cognitive development}

Language activity in cognitive linguistics is regarded as one of the models of cognition and it is based on cognitive skills that are non-linguistic but create prerequisites for language. A fundamental principle in this approach is the idea that it is not actually normal to focus on language separately from the cognitive activity of memory, attention, social contacts of people and other aspects of life experience (cf. Langacker 1987; Wierzbicka 1992; Gallese, Lakoff 2005). The very nature of language fits the extralinguistic reality - mental and social.

Language is a hierarchical system of symbols (signs), which human beings have created in order to name things and objects. And if the language system is a stratified triangle in which individual language elements can be represented, then each stratum represents a language level (lexicon, syntax, morphology, phonology, phonetics). On a higher level, Tsvetkova (2012) studied the English present progressive construction as part of the cognitive taxonomy of the 
constructions preceding it to prove that tense as part of grammar is also based on the preceding structures.

Language symbols, on the other hand, can name not only real objects but things that can be accepted through the senses as well - ideas, feelings, and intentions.

In the present study, language is considered not only as the production of sounds and words. It is a complex system that distinguishes humans from other creatures because language is a powerful tool of thinking. Language is investigated as a social tool that is used for sharing experience. Cognition, however, is a term that is used to include every system of belief, knowledge, understanding, interpretation, perception, etc.

\subsection{Language and perception}

Language and perception are deeply interrelated. On the one hand, correlations between perceptual dimensions build up non-linguistic categories and on the other hand, linguistic categories may agree with these non-linguistic categories if words correlate with the perceptual dimensions. Then we can describe what we perceive when using words. Thus linguistic behaviour and language acquisition are influenced by non-linguistic perception. The acquisition of words or structures is predetermined by specific perceptual mechanisms. Everybody's experience is different from that of the others. Everybody builds their own vocabulary and that is the reason why there are various nuances in the meanings of the words.

A child, for example, builds its vocabulary by learning new associations of words with ideas and objects. As Peneva (2013: 37) points out "the semantic meaning is usually about understanding human expressions through language and signs".

Taylor (1995: viii), on the other hand, assumes that linguistic objects are like non-linguistic objects:

Just as a botanist is concerned with a botanical categorisation of plants, so a linguist undertakes a linguistic categorisation of linguistic objects. ... If, as will be argued, categories of linguistic objects are structured along the same lines as the more familiar semantic categories, then any insights we may gain into the categorisation of the non-linguistic world may be profitably applied to the study of language structure itself.

Some cognitive linguists, Langacker (1987) among them, prove that that nonlinguistic psychological processes and dimensions such as visual scanning, imagery, colour, and depth influence the functional role of grammatical patterns. Based on this review, the same author asserts that in order to learn grammatical 
structures and words, the language learner needs a direct path from perceptual mechanisms to language learning mechanisms.

Language can also shape our understanding of the world through expressing the sounds and noise of fauna and nature - miaow, moo, quack, ruff, etc. All of them have their imitative nature. They are part of the non-linguistic semiotics that the subject of language uses, too.

The article extends the idea that there is difficulty in relating language to the context and the world in which it occurs, too, and it may arise from the fact that the way in which we see the world is to a certain extent dependent on the language we use. Since we categorise the objects of our experience with the aid of language, it may be the case that there are two aspects of learning - about the world and about language. They are activities that cannot be separated and therefore our world is partly determined by our language. Indeed, the Polish anthropologist Bronislaw Malinowski (1948) argued that primitive people use words only for the objects that stand out for them from the world. They pick out by words those parts that are relevant to them.

The finding appears at first glance to contradict the view which is expressed in the Sapir-Whorf hypothesis (Caroll 1956; Kay, Kempton 1984). Edward Sapir (1949) suggested that the world in which we live "is to a large extent unconsciously built up on the language habits of the group". Later on, his view was expanded and explained by Whorf (1956). Whorf is famous for his interest in some of the most significant problems in the relation between linguistic and non-linguistic phenomena.

We are unaware of the background character of our language, just as we are unaware of the presence of air until we begin to choke, and that if we look at other languages we come to realise that a language does not merely voice ideas, but that it is 'the shape of ideas' and that we dissect nature along lines laid down by our native language (Whorf 1956: 214).

This leads to a new principle of relativity which holds that all observers are not led by the same physical evidence to the same picture of the universe, unless their linguistic backgrounds are similar or in some way can be calibrated (Whorf 1956: 214). Another question arises from the case in which speakers of different languages have a different picture of the universe. We can have a similar picture to the picture that others have only if we understand their language. In another case, it may happen that we can meet difficulties in translation.

\subsection{Language and thought}

In the relationship between language and thought, the peculiarities of a given language determine the way a picture is described. Thus the same scene can be presented in different ways according to the language in which it occurs 
(Birner 1999). For example, Hopi* is a language which provides an explanation to this (Malotki 1983). Directions like left, right, front and back do not exist in it. Instead, the speakers use the words describing the four cardinal directions (east, west, north, and south). So, they would never say:

Turn right/left but Turn north/south/etc.

A man is standing in front of a house but $A$ man is standing north/etc. of the house.

So different languages certainly make us speak about space in very different ways.

Another reason lies in the verb form in the utterance. In English it refers to a past, present or future event.

John sleeps.

John slept.

John has been sleeping.

John will be sleeping.

In other languages, however, Chinese for example, it is not necessary to specify the time of the action because the same verb form can be used for past, present or future actions.

A research in the field (Deutscher 2010) has shown that even grammatical genders can shape the thoughts of the speaker. Words like teacher, neighbour, or friend oblige you to specify a certain type of information, sex in our case.

Another difference comes from the varying syntactical structures of different languages. It treats objects differently. In English, there are countable nouns which have two forms - one for the singular and another one for the plural as well as uncountable nouns which have only one form. There is not such a distinction in other languages, like Japanese. Instead, classifiers like a cup of are used for all nouns.

Sara Finley (2013) is also interested in the effects of non-linguistic experiences on linguistics. The question about the interaction between language and thought, she states, can be addressed not only as to whether language affects thought, but also whether non-linguistic information can have an effect on language.

"While language is a direct way to express one's thoughts", she points out, "there may be other, subtler ways, in which non-linguistic experience can affect

\footnotetext{
* Hopi is a Native American language spoken in northeastern Arizona. Whorf has studied it and his findings were used for comparison with the Western European languages, which he commonly lumped together as Standard Average European Languages.
} 
language". According to her, linguistic knowledge is specific to language because language is the key component to cognition and general to other cognitive processes because "the key to linguistic knowledge is an interaction between the need to communicate and the existence of high-level cognitive capacities such as abstract pattern learning and memory" (Chater, Christiansen 2010). According to the first view, cognition should have no influence on linguistic items while on the contrary, the second view illustrates that non-linguistic patterns have a strong influence on linguistic constructs.

\subsection{The influence of language on non-linguistic cognition}

Up until now, we can conclude that what is perceived influences the choice of words used to describe it and the acquisition of language. But does language have an influence on cognition? Loftus and Palmer (1974) argue that language can influence non-linguistic cognition in three possible ways. One of them concerns the wording of a particular utterance. Another one is associated with the context in which language occurs. Yet another focuses on the regularity that is implicit in the grammar or lexicon of a particular language. According to the authors, every description we hear forms particular images in our minds.

\section{Results and findings}

The article proves that language, perception, and thought are interdependent and the direction of interaction can go both from linguistic to non-linguistic patterns and vice versa.

According to Tacca (2011) "Perception and cognition are tightly related. Perceptual information guides our decisions and actions and shapes our beliefs. At the same time, our knowledge influences the way we perceive the world".

The question of language and thought needs to extend not only to whether language affects thought, but whether non-linguistic patterns can affect the way language is perceived. The article argues that our non-linguistic experience can affect the way we perceive language. The question that remains for future research is to understand when non-linguistic patterns may affect linguistic constructs in real-world situations.

\section{Conclusion}

There are a lot of ways in which linguistic and non-linguistic perception interact. They belong to a model of acquisition and have an important impact on language acquisition. The article stressed the role the non-linguistic context of an utterance plays in language acquisition.

This study was directed in accordance with the principles and procedures for cognitive-based learning as it relates to English as a foreign language. It contains 
all the elements of the traditional communication-oriented teaching as well as the cognitive-based strategy with the focus on learning and practice on the basis of comprehending linguistic knowledge and rules, inference of knowledge, structuring and arranging new knowledge units, storing and applying them. What is important to note is that in the integrated communicative and cognitive approach teaching is conducted through experimental learning. It is based on learning through the learner's experience with constructing and appropriating knowledge by means of English.

\section{Implications}

This body of findings illustrates the way the cognitive approach enhances the possibilities in EFL teaching. The non-linguistic context, which is most demanded of young learners or initial language acquisition, provides circumstances for students' efficient and successful experiences.

\section{References:}

Birner 1999: Birner B. (ed.). Does the Language I Speak Influence the Way I Speak? Linguistic Society of America. Advancing Scientific Study of language. $<$ https://www. linguisticsociety.org/content/does-language-i-speak-influence-way-i-think $>$ [Accessed 14 Oct. 2017].

Caroll 1956: Caroll J. B. Language, Thought, and Reality: Selected Writings of Benjamin Lee Whorf. Cambridge, Mass.: Massachusetts Institute of Technology Press.

Chater, Christiansen 2010: Chater N., M. Christiansen. Language Acquisition Meets Language Evolution. - Cognitive Science. 34 (7), 1131-1157.

Deutscher 2010: Deutscher G. Does Your Language Shape How You Think? - The New York Times Magazine. 29 August 2010. <http://www.nytimes.com/2010/08/29/ magazine/29language-t.html?mcubz $=3>$ [Accessed 14 Oct. 2017]

Finley 2013: Finley S. The Effect of Non-Linguistic Patterns on Linguistic Biases. Proceedings of the Annual Meeting of the Cognitive Science Society, 35, 2291-2296. $<$ https://pdfs.semanticscholar.org/aela/3b73c6dd69edeba955d5d9626a703b9669ac.pdf > [Accessed 14 Oct. 2017]

Gallese, Lakoff 2005: Gallese V., G. Lakoff. The Brain's Concept: The Role of the SensoryMotor System in Conceptual Knowledge. - Cognitive Neuropsychology. May, 22(3), 455-479.

Kay, Kempton 1984: Kay P., W. Kempton. What is the Sapir-Whorf hypothesis? - American Anthropologist. 86, 65-79.

Langacker 1987: Langacker R. W. Foundations of Cognitive Grammar: Theoretical prerequisites. Stanford University Press.

Loftus, Palmer 1974: Loftus E. F., J. C. Palmer. Reconstruction Of Automobile Destruction: An Example of the Interaction between Language and Memory. - Journal of Verbal Learning and Verbal Behavior. 13, 585-589.

Malinowski 1948: Malinowski B. Magic, Science and Religion and Other Essays. The Free Press: Glencoe, Illinois. 
Malotki 1983: Malotki E. Hopi Time: A Linguistic Analysis of the Temporal Concepts in the Hopi Language. Mouton Publishers. Berlin.

Peneva 2013: Peneva D. Quantitative and Qualitative Analysis of the Apology Speech Act „Sorry". - In: Todorova et al. (eds.). Dynamics, Interdisciplinarity, Diversity. Series in Linguistics, Culture and FLT. Konstantin Preslavsky University Press. Shumen. 29-42.

Piaget 1936: Piaget J. Origins of Intelligence in the Child. London: Routledge \& Kegan Paul.

Sapir 1949: Sapir E. Selected Writings of Edward Sapir in Language, Culture and Personality. Mandelbaum D. G. (ed.). Berkeley: University of California Press.160-166.

Slobin 1996: Slobin D. From "Thought and Language" to "Thinking for Speaking”. - In: GumperzJ. J., S. C. Levinson (eds.). Rethinking Linguistic Relativity.CUP.70-96.

Tacca 2011: Tacca M. Commonalities between Perception and Cognition. - Front Psychol. 2: 358. <https://www.ncbi.nlm.nih.gov/pmc/articles/PMC3227022/> [Accessed 14 Oct. 2017]

Taylor 1995: Taylor J. R. Linguistic Categorization: Prototypes in Linguistic Theory. Oxford: Oxford University Press.

Tsvetkova 2012: Tsvetkova $M$. Konstruktsiyata na segashno prodalzhitelno vreme $v$ angliyskiya ezik kato chast ot kognitivnata taksonomiya na predkhozhdashtite ya konstruktsii. - Godishnik na Shumenski universitet Episkop Konstantin Preslavski, Fakultet po khumanitarni nauki, tom XXIII A, Shumen: Universitetsko izdatelstvo. 256- 281.

Tsvetkova 2016: Tsvetkova M. Challenges in Teaching ESL to Young Learners. - In: Todorova et al. (eds.). Challenges in English Teaching and Research. Series in Linguistics, Culture and FLT. Vol 1. Asenevtsitrade Ltd.: Sofia. 125-135.

Whorf 1956: Whorf B. L. Language, Thought and Reality. Cambridge, MA: MIT Press. 207-219.

Wierzbicka 1992: Wierzbicka A. Semantics, Culture and Cognition: Universal Human Concepts in Culture-Specific Configurations. OUP. 